Vol. VII-1. April 2011

\title{
PENGARUH SUHU TERHADAP PEMIJAHAN KERANG MUTIARA Pinctada maxima (JAMESON)
}

\author{
Pitjont Tomatala
}

Teknologi Budidaya Perikanan, Politeknik Perikanan Negeri Tual.

\begin{abstract}
Pearl oysters, Pinctada maxima, are known as South Sea Pearl. Breeding is an important factor in intensive culture pearl oyster. In breeding, spawning became determining factor. The purpose of this research was to understand the effect of temperature decrease on the spawning level and to compare the treatment of water temperature decrease and increase on spawning level of pearl oyster $P$. maxima. The result showed that temperature decrease treatment influenced the success of the spawning level. Both water temperature decrease and increase had similar effect on the spawning level of the pearl oyster.
\end{abstract}

Key words: Spawning, temperature, oyster pearl Pinctada maxima

\section{PENDAHULUAN}

Kerang mutiara Pinctada maxima merupakan kerang penghasil mutiara berwarna emas dan perak yang sangat digemari. Kerang jenis ini sering disebut South Sea Pearl dan merupakan komoditi laut yang diekspor (Effendi dan Nikijuluw, 2003). Besarnya minat pasar internasional terhadap mutiara Indonesia menyebabkan kegiatan budidaya kerang jenis ini mengalami peningkatan pada beberapa gahun terakhir.

Peningkatan produksi mengharuskan ketersedian benih/induk kérang mutiara secara kontinyu baik jumlahcdah ukuran. Di lain pihak, benih yang dikasilkan oleh alam bervariasi dan tidak kontinyu. Hal ini menyebabkan kegiatan budidaya kerang mutiara harus memiliki tempat pembenihan (hactchery) guna pemenuhan kebutuhan benih/induk kerang.

Pemíjahan merupakan faktor penentu dalam kégiatan pembenihan. Pemijahan kerang mutiara $P$. maxima pada hatchery biasanya didahului dengan perangsangan dan rangsangan yang diberikan berupa manipulasi suhu. Berdasarkan beberapa penelitian sebelumnya, metode manipulasi suhu yang sering digunakan dalam pemijahan kerang mutiara yaitu fluktuasi suhu dengan menaikan suhu air (Erawati dkk, 2001; Doroudi dan Soouthgate, 2003; Winanto, 2004; Tomatala 2008). Sedangkan laporan mengenai pengaruh penurunan suhu terhadap pemijăhan kerang mutiara belum terekspos. Oleh karena itu, tujuan penelitian ini yaitu untuk mengetahui pengaruh pepurunan suhu terhadap tingkat pemijahan dari kerang mutiara $P$. maxima dan membandingkan metode menurunkan subu dan menaikkan suhu air terhadap tingkat pemijahan kerang mutiara $P$. maxima.

\section{METODE PENELITIAN}

Penelitian ini dilakukan di Laboratorium hatchery Pulau Kelapa Elat, Maluku Tenggara dan berlangsung pada bulan Oktober 2010. Alat yang digunakan dalam penelitian ini antara lain pembuka cangkang, spatula, kotak gabus sintetis, bak kaca serat, senter, sikat pakaian, keranjang plastik, pemanas, pendingin, termometer, refraktometer, $\mathrm{pH}$ meter dan stopwatch. Bahan yang digunakan yaitu induk kerang, fitoplankton (Tetraselmis sp.) dan air laut bersih.

\section{Persiapan}

Induk kerang yang digunakan dalam pemijahan yaitu induk kerang hasil tangkapan dari alam yang telah didomestifikasi. Kerang yang digunakan dalam pemijahan yaitu kerang yang benar-benar matang gonad (TKG IV) berdasarkan klasifikasi menurut Chellam (1987). Kerang yang telah dipilih kemudian dibersihkan dari biofouling yang menempel. Selain itu, dilakukan juga 
pengukuran kualitas air (suhu, salinitas, dan $\mathrm{pH}$ ) dimana kerang diambil. Kerang yang telah dibersihkan kemudian diletakkan secara terpisah (jantan dan betina tersendiri) pada bak kaca serat dan diberi pakan berupa Tetraselmis sp. Sekitar 30 menit setelah pemberian pakan, kerang diambil dan diletakkan dalam keranjang dengan kepadatan 10 individu/keranjang. Selanjutnya kerang tersebut siap dirangsang pada wadah perangsangan.

\section{Perangsangan Penaikan Suhu}

Kotak gabus sintetis sebagai wadah perangsangan diisi dengan air laut bersih dengan suhu air $29^{\circ} \mathrm{C}$. Suhu air dinaikkan secara bertahap dengan menggunakan pemanas sampai suhu air mencapai $34^{\circ} \mathrm{C}$. Kemudian kerang dimasukkan ke dalam wadah perangsangan dan dibiarkan selama 30 menit. Selama kurung waktu tersebut, diamati perubahan fisiologi dan pemijahan yang terjadi. Perlakuan ini diulangi sebanyak tiga kali ulangan dengan jumlah individu perulangan sebanyak 10 individu.

\section{Perangsangan Penurunan Suhu}

Perlakuan dengan penurunan suhu air menggunakan metode yang hampir sama pada metode di atas, namun yang berbeda yaitu suhu air awal $\left(29^{\circ} \mathrm{C}\right)$ diturūkan menjadi $24^{\circ} \mathrm{C}$ dengan menggunakan pendingin. Jumlah kerang yang digunakan dan banyaknya ulangan yang dilakukan sama seperti pada perlakuan manaikan suhu air.

Selama perangsangan, kondisi ruangan harus gelap. Selain kedua perlakuan tersebut, ada jưga kontrol. Pada kontrol, tidak dilakukan manipulasi suhu. Hasil pengamatan terhadap kedua perlakuan (menaikkan dan menurunkan suhu air) akan diuji secara statistik menggunakan uji t untuk mengetahui perbedaan di antara keduanya.

\section{HASIL DAN PEMBAHASAN}

Sebelum pemijahan, kualitas air (suhu, salinitas dan $\mathrm{pH}$ ) pada semua wadah eksperimen disesuaikan dengan kualitas air pada habitat dimana induk diambil. Kualitas air tersebut yaitu suhu $29^{\circ} \mathrm{C}$, salinitas 32 $\mathrm{ppm}$, dan $\mathrm{pH} 7,6$. Penyesuaian kualitas air tersebut bertujuan untuk menghindari te- kanan pada induk yang dapat menyebabkan terjadinya pemijahan secara liar.

Pemijahan adalah proses pelepasan gamet oleh individu jantan dan betina. Kerang yang mendapat perlakuan menaikkan dan menurunkan suhu air ternyata melakukan pemijahan, sedangkan pada kontrol tidak ditemui adanya pemijahan (Gambar 1). Diasumsikan, terjadinya pemijahan disebabkan oleh adanya perubahan suhu. Eallu (1991) menyatakan bahwa perubahan temperatur air secara mendadak dapat menyebabkan induk kerang melepaskan gametnya. Hal senada juga diutarakan oleh Stoeckel et al. (2004) bahwa sejumlah besar spesies melakukan pemijahan bilamana terjadi perubahan lingkungan.

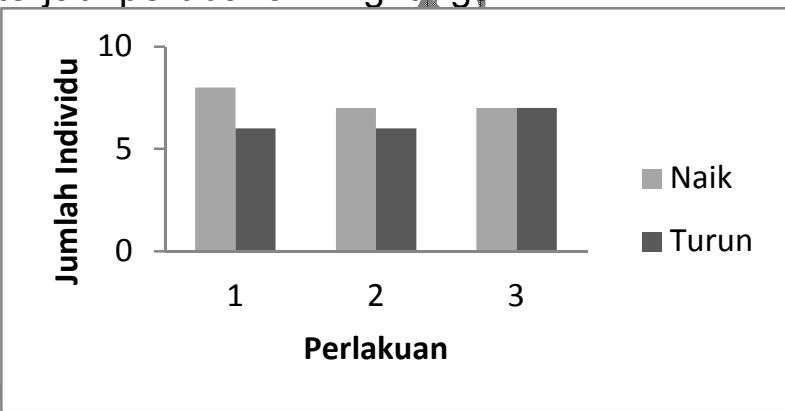

Gambar 1. Grafik hasil perlakuan (menaikkan dan menurunkan suhu).

Pemijahan yang terjadi didahului dengan gejala-gejala tekanan yang ditandai dengan pergerakan cangkang (buka tutup cangkang) dengan cepat dan terjadi pelepasan tinja. Saat akan melakukan pemijahan, cangkang terbuka dan gamet (sperma dan telur) disemburkan ke luar tubuh. Gamet yang dikeluarkan terlihat menyerupai kepulan asap. Pelepasan gamet tidak terjadi secara serempak melainkan secara bertahap.

Waktu yang dibutuhkan untuk melakukan pemijahan dari kedua perlakuan ternyata tidak berbeda jauh. Kerang yang dirangsang dengan menaikan suhu air mengeluarkan gametnya sekitar 15-25 menit setelah perangsangan, sedangkan 17-27 menit untuk kerang yang dirangsang dengan menurunkan suhu air. Ini menandakan bahwa perubahan lingkungan mempengaruhi proses pemijahan. Hal tersebut sesuai dengan pernyataan Fallu (1991) bahwa pelepasan gamet (sperma dan telur) berkaitan dengan perubahan lingkungan.

Pada kontrol tidak ada kerang yang memijah. Ini diakibatkan karena tidak terja- 
di perubahan lingkungan yang disebabkan oleh tidak adanya perangsangan. Menurut Kafuku and Ikenoue (1983), perubahan kondisi lingkungan dapat mempengaruhi aktivitas kerang mutiara. Hal yang sama pula diungkapkan oleh Winanto (2004) bahwa perlu adanya rekayasa pemijahan jika secara alami kerang mutiara tidak mau memijah di dalam wadah pemijahan.

Berdasarkan hasil uji t terhadap kedua perlakuan (menaikkan dan menurunkan suhu) diketahui $t_{\text {hit. }}(1,730)<t_{\text {tab. }} 0,05$ $(4,30)$ yang mengindikasikan bahwa kedua perlakuan tersebut memiliki pengaruh yang sama terhadap tingkat pemijahan kerang mutiara $P$. maxima.

\section{KESIMPULAN}

Berdasarkan hasil pembahasan diperoleh kesimpulan yaitu:

Manipulasi lingkungan dengan metode menurunkan suhu air dapat mempengaruhi keberhasilan pemijahan kerang mutiara $P$. maxima.

Metode menurunkan dan menaikkan suhu air memiliki pengaruh yang sama terhadap tingkat pemijahan kerang mutiara $P$ maxima.

\section{UCAPAN TERIMA KASIH}

Diucapkan terima kasih kepdda Bapak Jemi Djuanda selaku pemilik perusahaan yang telah membantu Selama penelitian ini berlangsung sehingga penelitian ini terlaksana dengan baik.

\section{DAFTARPUSTAKA}

Chellam, A. 4987. Biology of Pearl Oyster Pinctada fucata (Gould). Central marine fisheries research institute. India. 136p.
Doroudi, M.S., and P.C. Soouthgate, 2003. Embryonic and Larval Development Of Pinctada margaritifera (Linnaeus, 1758). Molluscan Research. www.publishing csiro.au.

Effendi, I., dan V. Nikijuluw, 2003. Pedoman Investasi Komoditas Mutiara di Indonesia. Direktorat Jenderal Peningkatan Kapasitas Kelembagaan dan Pemasaran. Departemen Perikanan dan Kelautan. Jakarta. 23 hal.

Erawati, L., T. Winanto, dan B.D. Silwester, 2001. Pembenihan Tiram Mutiara (Pinctada maxima). Direktoral Jenderal Perikanan Budidaya. Balaí Budidaya Laut. Lampung. 54 hal

Fallu, R., 1991. Abatone Farming. Fishing News Books. England. 195p.

Kafuku, I., and H. Mkenoue, 1993. Modern Method of Aquaculture Japan. Development in aqu'culture and fisheries science. vol II

Stoecker, J.A., D.K. Padiila., D.W. Schneider, and C.R. Rehmann, 2004. Laboratory Culture of Dreissena Polymorpha Larvae: Spawning Success, Adult Fecundity and Larval Mortality Patterns. The NRC Research Press. Canada. 1436-1443p.

Tomatala, P., 2008. Pengaruh makanan pada pertumbuhan dan pengaruh kolektor pada penempelan larva kerang Pictada maxima (Jameson). Tesis. UNSRAT.

Winanto, T., 2004. Memproduksi Benih Tiram Mutiara. Penebar Swadaya. Jakarta. 95 hal. 